\title{
Fibroblast growth factor receptor 4 as a prognostic indicator in triple-negative breast cancer
}

\author{
Wei Wei ${ }^{1 \#}$, Shiyu Cao ${ }^{2 \#}$, Jing Liu ${ }^{3}$, Yuhang Wang ${ }^{2}$, Quanfu Song ${ }^{4}$, Leha A ${ }^{4}$, Shanshan Sun ${ }^{2}$ Xianyu Zhang ${ }^{2}$, \\ Xiaoshuan Liang', Yongdong Jiang ${ }^{2}$ \\ ${ }^{1}$ Department of Breast Surgery, Zhujiang Hospital of Southern Medical University, Guangzhou, China; ${ }^{2}$ Department of Breast Surgery, Harbin \\ Medical University Cancer Hospital, Harbin, China; ${ }^{3}$ Department of Anesthesiology, The Second Affiliated Hospital, Harbin Medical University, \\ Harbin, China; ${ }^{4}$ Department of Oncology, Altay District People's Hospital, Altay, China \\ Contributions: (I) Conception and design: W Wei, S Cao, X Liang, Y Jiang; (II) Administrative support: X Liang, Y Jiang; (III) Provision of study \\ materials or patients: J Liu, Y Wang, Q Song, L A; (IV) Collection and assembly of data: J Liu, Y Wang, Q Song, L A; (V) Data analysis and \\ interpretation: W Wei, S Cao, S Sun, X Zhang; (VI) Manuscript writing: All authors; (VII) Final approval of manuscript: All authors. \\ \#These authors contributed equally to this work. \\ Correspondence to: Xiaoshuan Liang; Yongdong Jiang. Department of Breast Surgery, Harbin Medical University Cancer Hospital, Harbin, China. \\ Email: liangxs1982@sina.com; jiangyongdonghmu@126.com.
}

Background: Triple-negative breast cancer (TNBC) constitutes up to $15 \%$ of all breast cancers. It is one
of the most aggressive breast cancers and is more prone to metastasize compared with other subtypes. Breast
cancer patients with this subtype usually have a poor prognosis. Fibroblast growth factor receptor 4 (FGFR4)
belongs to the receptor tyrosine kinase (RTK) family, and early analyses identified that FGFR4 was involved
in breast cancer. However, the prognostic effect of FGFR4 on TNBC is unknown. In the present study, we
investigated the association between FGFR4 and TNBC prognosis. Methods: A total of 282 TNBC patients were enrolled. FGFR4 protein expression was detected in these 282 TNBC patients using immunohistochemistry (IHC).

Results: In the present study, FGFR4 was highly expressed in TNBC patients. Lymph node metastasis (LNM) $(\mathrm{P}=0.033)$ and $\mathrm{p} 53$ status $(\mathrm{P}=0.019)$ were associated with high FGFR4 expression. Univariate analysis identified high FGFR4 expression $(\mathrm{P}=0.016)$ as a prognostic predictor, and multivariate analysis found that high FGFR4 expression ( $\mathrm{P}=0.016)$ was an independent prognostic factor. The Kaplan-Meier survival curve showed that high FGFR4 protein expression was correlated with poorer overall survival (OS).

Conclusions: The results of our present study show that FGFR4 protein expression is correlated with a worse prognosis in TNBC.

Keywords: Fibroblast growth factor receptor 4 (FGFR4); immunohistochemistry (IHC); triple-negative breast cancer (TNBC); prognosis

Submitted Apr 02, 2020. Accepted for publication Sep 26, 2020.

doi: $10.21037 /$ tcr-20-1756

View this article at: http://dx.doi.org/10.21037/tcr-20-1756

\section{Introduction}

Triple-negative breast cancer (TNBC) is one of the four major molecular subtypes of breast cancer (1). It is characterized as loss of expression of estrogen receptors (ERs), progesterone receptors (PRs) and human epidermal growth factor receptor 2 (HER2), and it is one of the most aggressive breast cancer subtypes and is more prone to metastasize compared with other subtypes (2-4). Although several genes and proteins have been identified as prognostic indicators or therapeutic targets in breast cancer, there is still a lack of therapeutic targets for TNBC (5-7). TNBC patients usually have a poor prognosis and a high rate of recurrence after chemotherapy $(8,9)$. Thus, 
prognostic indicators or therapeutic targets of TNBC still need to be identified.

Fibroblast growth factor receptor 4 (FGFR4) is a member of the FGFR family, which is part of the receptor tyrosine kinase (RTK) family (10). FGFR4 is encoded by FGFR 4 gene, which is located at chromosome $5 \mathrm{q} 35$-qter (11). FGFR4 shares the conserved structure with other FGFRs, but the FGFR4 gene codes only one isoform (12). Previous studies have shown that FGFR4 may be involved in the carcinogenesis and progression of many cancers (13-16). FGFR4 has also been implicated in breast cancer. FGFR4 can increase glucose metabolism and lead to chemoresistance (17), and the FGF19/FGFR4 axis can enhance basal-like breast cancer cell survival and might be an effective strategy to suppress cancer development, progression and metastasis $(18,19)$. There have been almost no studies on the prognosis of FGFR4 in TNBC, so in the present study, we investigated the association between FGFR4 and TNBC prognosis through immunohistochemistry (IHC) analyses.

We present the following article in accordance with the REMARK reporting checklist (available at http://dx.doi. org/10.21037/tcr-20-1756).

\section{Methods}

\section{Subjects}

A total of 282 primary breast cancer patients from November 2008 to March 2011 were included. Patients with sporadic breast cancer underwent initial diagnosis and resection at Harbin Medical University Cancer Hospital. Patients did not receive any chemotherapy or radiotherapy before surgery. Routine testing for ER, PR, HER2, p53 and Ki67 was performed for every patient. TNBC patients were included with invasive ductal carcinomas histological type. All procedures performed in this study involving human participants were in accordance with the 1964 Helsinki Declaration and its later amendments or comparable ethical standards. Written informed consent was obtained from every participant. This study was approved by the ethics committee of Harbin Medical University and carried out in accordance with approved guidelines.

\section{Patient follow-up}

Patient follow-up was conducted as our previous study (20). It was conducted on a scheduled basis until patient death or the end of the observation period (May 1st, 2016). Examinations were carried out every 6 months for the first 2 years and every 12 months thereafter. All patients were followed regularly for at least 5 years at Harbin Medical University Cancer Hospital. Every patient was contacted by telephone after terminal treatment. Survival time was calculated in months. Overall survival (OS) was used to assess prognosis.

\section{IHC}

A total of 282 samples from patients were randomly selected for IHC analyses. FGFR4 IHC was performed using a rabbit anti-FGFR4 monoclonal antibody (1:200 dilution, Abcam: ab41948) as previously described (20).

IHC for ER, PR, HER2, Ki67 and p53 (ZSBG-BIO: ZM-0104, ZM-0215, ZM-0065, ZM-0165, ZM-0405) was performed similarly. Staining for ER and PR was considered negative if $<1 \%$ of tumor cell nuclei were stained (21). The expression of HER2 was evaluated with the HercepTest kit (Dako) and scored as 0,1+, 2+ and 3+. Scores of 0 and $1+$ were considered to be negative. Scores of $2+$ were insufficient to determine positive or negative status; thus, HER2/neu status confirmed by fluorescence in situ hybridization (FISH) was added (22). Ki67 scores of $30 \%$ or above were considered positive (23). p53 status was defined as positive when more than $10 \%$ of the tumor cells stained positive (24).

The expression of FGFR4 was evaluated by multiplying the intensity by the percent reactivity extension values. The intensity of staining was scored as no staining [0], weak staining [1], moderate staining [2] and strong staining [3], while the percent reactivity extension value was scored as a continuous variable $(<10 \%=0,10-30 \%=1,30-50 \%=2$, $>50 \%=3)$. A cut-off value of 4 was used to categorize FGFR4 expression into high and low (25). All staining was scored by the original two pathologists and a senior pathologist.

\section{Statistical analysis}

We performed statistical analyses with SPSS software version 22.0 (SPSS, Chicago, IL, USA). We used the chisquare test to conduct the association analysis between FGFR4 protein expression and clinicopathological variables. A Cox regression model was performed for univariate and multivariate survival analyses, and the Kaplan-Meier method was employed to estimate the OS 
Table 1 Summary of patient characteristics

\begin{tabular}{|c|c|}
\hline Characteristics & Frequency, n (\%) \\
\hline Patients (n) & 282 \\
\hline Age & $49.6 \pm 10.2$ \\
\hline \multicolumn{2}{|l|}{ pTNM stage } \\
\hline I, II & 218 (77.3) \\
\hline III & $64(22.7)$ \\
\hline \multicolumn{2}{|l|}{ Tumour size $(\mathrm{cm})$} \\
\hline$\leq 2$ & $249(88.3)$ \\
\hline$>2$ & $33(11.7)$ \\
\hline \multicolumn{2}{|c|}{ Pathological grade } \\
\hline II & $195(69.1)$ \\
\hline III & 87 (30.9) \\
\hline \multicolumn{2}{|l|}{ LNM } \\
\hline Negative & $159(56.4)$ \\
\hline Positive & $123(43.6)$ \\
\hline \multicolumn{2}{|c|}{ Vessel cancer embolus } \\
\hline Negative & 252 (89.4) \\
\hline Positive & $30(10.6)$ \\
\hline \multicolumn{2}{|l|}{ Ki67 status } \\
\hline$<30 \%$ & $95(33.7)$ \\
\hline$\geq 30 \%$ & $187(66.3)$ \\
\hline \multicolumn{2}{|l|}{ p53 status } \\
\hline Negative & $137(48.6)$ \\
\hline Positive & 145 (51.4) \\
\hline
\end{tabular}

LNM, lymph node metastasis.

of TNBC patients. $\mathrm{P}<0.05$ was considered statistically significant.

\section{Results}

\section{Patient characteristics}

A total of 282 TNBC patients were enrolled in the present study. Patient characteristics: the mean age of the patients was $49.6 \pm 10.2$. A total of 218 patients $(77.3 \%)$ and 64 patients $(22.7 \%)$ were classified as stage I/II and stage III, respectively. There were 249 patients $(88.3 \%)$ whose tumor diameters were less than or equal to $2 \mathrm{~cm}$, whereas $33(11.7 \%)$ had tumor diameters greater than $2 \mathrm{~cm}$. Other detailed clinicopathological features of the patients are shown in Table 1.

\section{Associations between FGFR4 protein expression and clinicopathological features in TNBC}

The expression of FGFR4 protein is shown in Figure 1. In total, 154 (54.6\%) patients had high FGFR4 expression, and the remaining 128 (45.4\%) had low FGFR4 expression. As indicated in Table 2, statistically significant associations between high expression of FGFR4 and LNM and p53 status were noted. Patients with high FGFR4 expression were more likely to have $\mathrm{LNM}(\mathrm{P}=0.033, \mathrm{R}=0.127)$ and p53-positive status $(\mathrm{P}=0.019, \mathrm{R}=0.140)$. Nevertheless, the associations between high FGFR4 status and other clinicopathological characteristics, such as pTNM stage, tumor size, pathological grade, vessel cancer embolus and status of Ki67, were not significant.

\section{Univariate and multivariate analyses of the prognostic value of FGFR4 expression in TNBC}

We conducted univariate and multivariate analyses to evaluate the clinical prognostic value of FGFR4 in patients with TNBC (Table 3). The univariate analysis was performed first, and the results showed that pTNM stage $(\mathrm{P}<0.001)$, tumor size $(\mathrm{P}=0.03), \mathrm{LNM}(\mathrm{P}=0.002)$, Ki67 status $(\mathrm{P}=0.007)$ and FGFR4 expression $(\mathrm{P}=0.016)$ were significant prognostic predictors in the present population. There was no prognostic value of other features. Furthermore, the statistically significant factors $(\mathrm{P}<0.05)$ were selected for a final model to perform multivariate analysis on the same group of patients. pTNM stage $(\mathrm{P}=0.004)$, Ki67 status $(\mathrm{P}=0.017)$ and FGFR4 expression $(\mathrm{P}=0.016)$ were found to be independent prognostic factors, whereas tumor size and LNM were not.

\section{Kaplan-Meier survival analysis}

Kaplan-Meier analysis was used to evaluate the survival of TNBC patients. The survival information for the patients is shown in Figure 2. TNBC patients with high FGFR4 expression were likely to have significantly poorer OS $(\mathrm{P}=0.015)$. It was suggested that high FGFR4 expression 

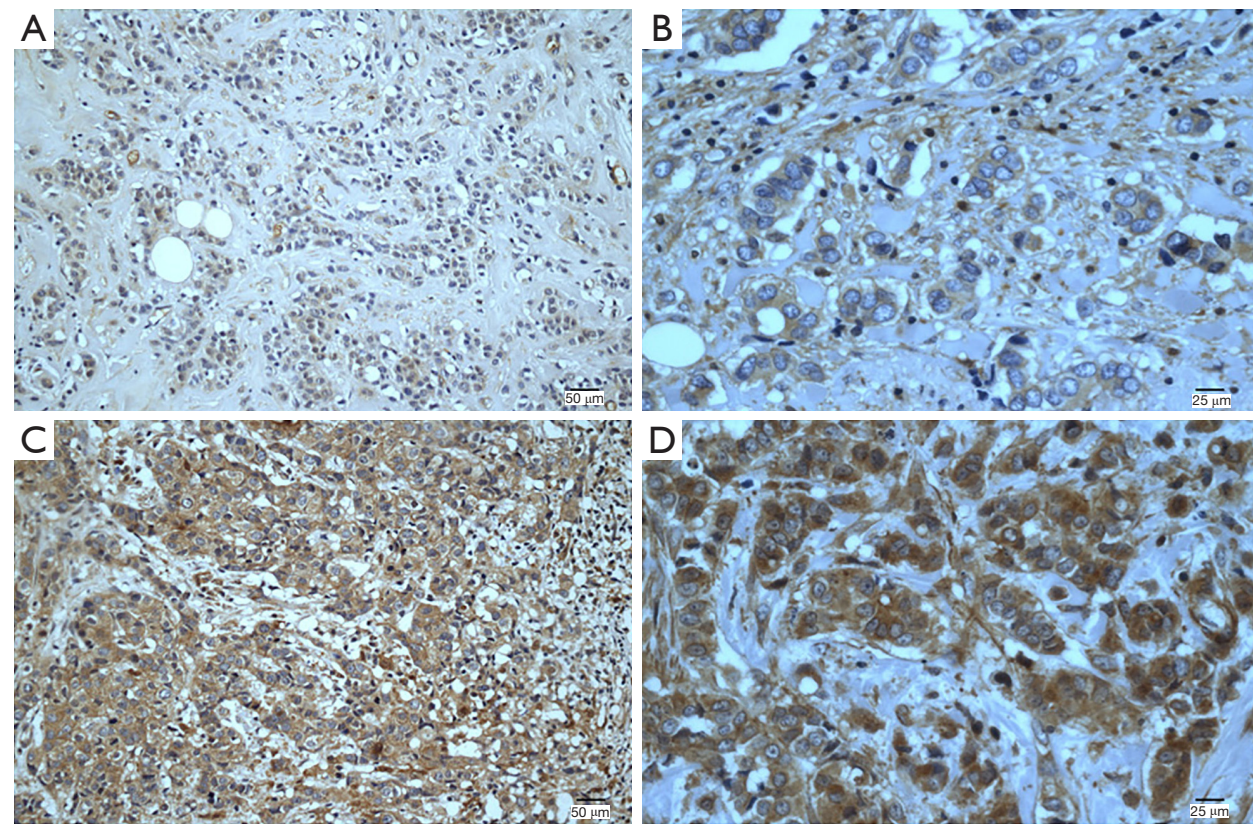

Figure 1 Immunohistochemical staining of FGFR4 in TNBC tissues. Staining for each specimen is shown at two magnifications: (A,C) 200×; (B,D) 400×. FGFR4 protein low-expression specimens (A,B); FGFR4 protein high-expression specimens (C,D). FGFR4, fibroblast growth factor receptor 4; TNBC, triple-negative breast cancer.

was associated with worse OS in TNBC patients.

\section{Discussion}

To investigate the role of FGFR4 in TNBC, we evaluated a substantially large patient cohort with long-term follow-up by analysis of FGFR4 protein expression and its association with clinicopathological features. A total of 282 TNBC patients were enrolled for evaluation via IHC. Our results revealed that high expression of the FGFR4 protein was associated with LNM and $\mathrm{p} 53$ status. Univariate analysis indicated that FGFR4 protein expression might be a prognostic predictor, and multivariate analysis showed that FGFR4 protein expression was an independent prognostic factor. Kaplan-Meier curves showed that high expression of FGFR4 protein was associated with worse outcomes. No significant correlation between FGFR4 expression and other clinical characteristics was found.

FGFR4 is encoded by the FGFR4 gene, which is located at chromosome 5q35-qter (11). Physiologically, FGFR4 is involved in embryonic development, angiogenesis and tissue differentiation (26) and participates in regulating bile acid production, metabolism, muscle differentiation and tissue repair (27-30). FGFR4 is also involved in cancer development and progression.
Previous studies have shown that FGFR4 protein is highly expressed in many cancers, such as lung cancer, gastric cancer, colorectal cancer, and breast cancer $(16,25,31,32)$. The present study is in line with those. FGFR4 was highly expressed in our TNBC patients, among whom 154 (54.6\%) had high FGFR4 expression. Inokuchi et al. (16) and Murase et al. (33) found that high expression of FGFR4 was associated with LNM in gastric cancer, and the FGFR4 polymorphism Gly388Arg was reported to be correlated with LNM in many cancers $(11,34,35)$. We also found that high levels of FGFR4 expression had a relationship with LNM in our previous study (20). Consistent with these findings, our data revealed that high FGFR4 expression was correlated with LNM in TNBC patients. In addition, a significant correlation was observed between FGFR4 and the status of p53. However, there was no correlation between these factors in gastric cancer (36). The reasons for the opposite results might be different types of cancer or individual differences. Mutations in p 53 are the most common mutations in TNBC, and approximately $60-88 \%$ of TNBC or basal-like breast cancers have p53 mutations $(37,38)$. Many studies have reported that $\mathrm{p} 53$ status could affect chemotherapy responsiveness, but the findings were controversial. Bae et al. (39) reported that p53 positivity in TNBC was more sensitive to chemotherapy, 
Table 2 Correlation between FGFR4 expression and clinicopathological characteristics in TNBC

\begin{tabular}{|c|c|c|c|c|}
\hline Characteristics & Cases & \multicolumn{2}{|c|}{ FGFR4 protein expression } & $P$ value \\
\hline pTNM stage & & & & 0.558 \\
\hline I, II & 218 & $117(53.7)$ & $101(46.3)$ & \\
\hline III & 64 & $37(57.8)$ & $27(42.2)$ & \\
\hline$\leq 2$ & 249 & $134(53.8)$ & $115(46.2)$ & \\
\hline$>2$ & 33 & $20(60.6)$ & $13(39.4)$ & \\
\hline Pathological grade & & & & 0.155 \\
\hline II & 195 & $101(51.8)$ & $94(48.2)$ & \\
\hline Negative & 159 & $78(49.1)$ & $81(50.9)$ & \\
\hline Positive & 123 & $76(61.8)$ & $47(38.2)$ & \\
\hline Vessel cancer embolus & & & & 0.811 \\
\hline Negative & 252 & $137(54.4)$ & $115(45.6)$ & \\
\hline Positive & 30 & $17(56.7)$ & $13(43.3)$ & \\
\hline Ki67 status & & & & 0.824 \\
\hline Negative & 95 & $51(53.7)$ & $44(46.3)$ & \\
\hline Positive & 187 & $103(55.1)$ & $84(44.9)$ & \\
\hline
\end{tabular}

FGFR4, fibroblast growth factor receptor 4; TNBC, triple-negative breast cancer; LNM, lymph node metastasis.

Table 3 Prognostic factors in the Cox proportional hazards model

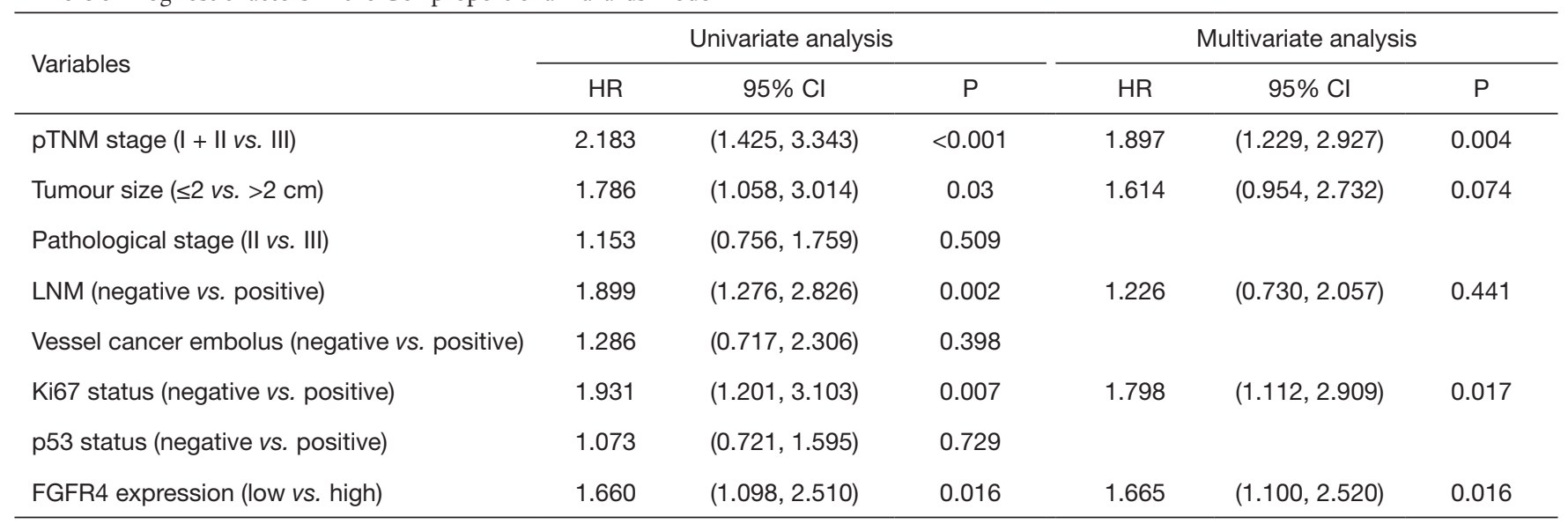

LNM, lymph node metastasis; FGFR4, fibroblast growth factor receptor 4. 


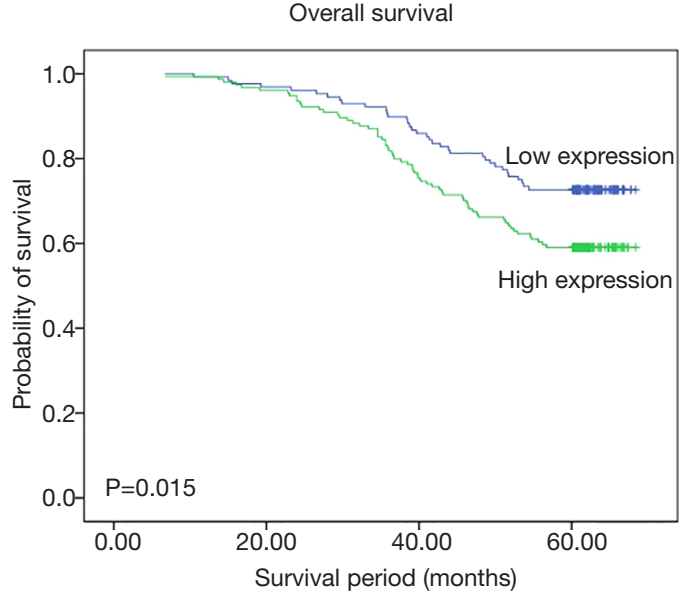

Figure 2 Kaplan-Meier analysis for OS of the TNBC patients included in this study based on the expression of the FGFR4 protein. OS, overall survival; TNBC, triple-negative breast cancer; FGFR4, fibroblast growth factor receptor 4.

but Giannakakou et al. (40) found that loss of functional p53 might facilitate the development of resistance. FGFR4 had a relationship with p53 in this study, which implies that FGFR4 may be involved in the chemotherapy responsiveness of TNBC. Thussbas et al. suggested that the FGFR4 polymorphism Gly388Arg was associated with resistance to chemotherapy in breast cancer (41). Tiong et al. found that FGFR4 and FGF19 autocrine enhanced basal-like breast cancer cell survival (19). Xu et al. found that high levels of FGFR4 increased glucose metabolism and led to chemoresistance in breast cancer (17).

The impact of FGFR4 on prognosis has been found in different cancers $(16,25,31)$, and we also confirmed that patients with high FGFR4 expression had worse outcomes (20). In the present study, TNBC patients with high FGFR4 expression tended to have shorter survival times than those with low FGFR4 expression (Figure 2). Our univariate analysis indicated that FGFR4 had prognostic value, and multivariate analysis indicated that FGFR4 was an independent prognostic indicator (Table 3). These findings suggest that FGFR4 may have important effects on TNBC. In clinical, we can use FGFR4 as therapeutic target in TNBC patients, as many FGFR4 inhibitors are under development. Furthermore, we can evaluate the prognosis of TNBC patients by FGFR4 because of its prognostic implication.

\section{Conclusions}

In summary, we investigated the relationship between FGFR4 protein expression and TNBC prognosis, and we confirmed that FGFR4 had an effect on TNBC. FGFR4 was correlated with LNM, p53 status and a worse TNBC prognosis. Our findings suggest that FGFR4 may be used as a prognostic marker for TNBC. Because of the scale and method of our study, there are still many limitations. Therefore, more studies are needed to determine the detailed mechanism of action of FGFR4.

\section{Acknowledgments}

The authors wish to thank all the study participants and staff.

Funding: These works including the study design and execution, the collection, analysis, and interpretation of data and writing the manuscript were supported by the National Natural Science Foundation of China (Grant No. 81202075) and the China Postdoctoral Science Fund (Grant No. 2015 M571445).

\section{Footnote}

Reporting Checklist: The authors have completed the REMARK reporting checklist. Available at http://dx.doi. org/10.21037/tcr-20-1756

Data Sharing Statement: Available at http://dx.doi. org/10.21037/tcr-20-1756

Peer Reviewv File: Available at http://dx.doi.org/10.21037/tcr20-1756

Conflicts of Interest: All authors have completed the ICMJE uniform disclosure form (available at http://dx.doi. org/10.21037/tcr-20-1756). The authors have no conflicts of interest to declare.

Ethics Statement: The authors are accountable for all aspects of the work in ensuring that questions related to the accuracy or integrity of any part of the work are appropriately investigated and resolved. This study was approved by the ethics committee of Harbin Medical University. All procedures performed in this study 
involving human participants were in accordance with the 1964 Helsinki Declaration and its later amendments or comparable ethical standards. Written informed consent was obtained from all individual participants included in the study.

Open Access Statement: This is an Open Access article distributed in accordance with the Creative Commons Attribution-NonCommercial-NoDerivs 4.0 International License (CC BY-NC-ND 4.0), which permits the noncommercial replication and distribution of the article with the strict proviso that no changes or edits are made and the original work is properly cited (including links to both the formal publication through the relevant DOI and the license). See: https://creativecommons.org/licenses/by-nc-nd/4.0/.

\section{References}

1. DeSantis CE, Ma J, Goding Sauer A, et al. Breast cancer statistics, 2017 , racial disparity in mortality by state. CA Cancer J Clin 2017;67:439-48.

2. Zeng K, He B, Yang BB, et al. The pro-metastasis effect of circANKS1B in breast cancer. Mol Cancer 2018;17:160.

3. Foulkes WD, Smith IE, Reis-Filho JS. Triple-negative breast cancer. N Engl J Med 2010;363:1938-48.

4. Metzger-Filho O, Tutt A, de Azambuja E, et al. Dissecting the heterogeneity of triple-negative breast cancer. J Clin Oncol 2012;30:1879-87.

5. Olopade OI, Grushko TA, Nanda R, et al. Advances in breast cancer: pathways to personalized medicine. Clin Cancer Res 2008;14:7988-99.

6. Sun S, Jiang Y, Zhang G, et al. Increased expression of fibroblastic growth factor receptor 2 is correlated with poor prognosis in patients with breast cancer. J Surg Oncol 2012;105:773-9.

7. Li YW, Xu J, Zhu GY, et al. Apigenin suppresses the stem cell-like properties of triple-negative breast cancer cells by inhibiting YAP/TAZ activity. Cell Death Discov 2018;4:105.

8. Cinkaya A, Akin M, Sengul A. Evaluation of treatment outcomes of triple-negative breast cancer. J Cancer Res Ther 2016;12:150-4.

9. Anders CK, Carey LA. Biology, metastatic patterns, and treatment of patients with triple-negative breast cancer. Clin Breast Cancer 2009;9 Suppl 2:S73-81.

10. Katoh M, Nakagama H. FGF receptors: cancer biology and therapeutics. Med Res Rev 2014;34:280-300.

11. Jiang Y, Sun S, Wei W, et al. Association of FGFR3 and FGFR4 gene polymorphisms with breast cancer in Chinese women of Heilongiiang province. Oncotarget 2015;6:34023-9.

12. Tang S, Hao Y, Yuan Y, et al. Role of fibroblast growth factor receptor 4 in cancer. Cancer Sci 2018;109:3024-31.

13. Motylewska E, Stepien T, Borkowska M, et al. Alteration in the serum concentrations of FGF19, FGFR4 and betaKlotho in patients with thyroid cancer. Cytokine 2018;105:32-6.

14. Quintanal-Villalonga Á, Ojeda-Márquez L, Marrugal Á, et al. The FGFR4-388arg variant promotes lung cancer progression by $\mathrm{N}$-cadherin induction. Sci Rep 2018;8:2394.

15. Joshi JJ, Coffey H, Corcoran E, et al. H3B-6527 is a potent and selective inhibitor of FGFR4 in FGF19-driven hepatocellular carcinoma. Cancer Res 2017;77:6999-7013.

16. Inokuchi M, Murase H, Otsuki S, et al. Different clinical significance of FGFR1-4 expression between diffuse-type and intestinal-type gastric cancer. World J Surg Oncol 2017;15:2.

17. Xu M, Chen S, Yang W, et al. FGFR4 links glucose metabolism and chemotherapy resistance in breast cancer. Cell Physiol Biochem 2018;47:151-60.

18. Zhao X, Xu F, Dominguez NP, et al. FGFR4 provides the conduit to facilitate FGF19 signaling in breast cancer progression. Mol Carcinog 2018;57:1616-25.

19. Tiong KH, Tan BS, Choo HL, et al. Fibroblast growth factor receptor 4 (FGFR4) and fibroblast growth factor 19 (FGF19) autocrine enhance breast cancer cells survival. Oncotarget 2016;7:57633-50.

20. Wei W, You Z, Sun S, et al. Prognostic implications of fibroblast growth factor receptor 4 polymorphisms in primary breast cancer. Mol Carcinog 2018;57:988-96.

21. Hammond ME, Hayes DF, Dowsett M, et al. American Society of Clinical Oncology/College of American Pathologists guideline recommendations for immunohistochemical testing of estrogen and progesterone receptors in breast cancer. J Clin Oncol 2010;28:2784-95.

22. Hsu CY, Ho DM, Yang CF, et al. Interobserver reproducibility of Her-2/neu protein overexpression in invasive breast carcinoma using the DAKO HercepTest. Am J Clin Pathol 2002;118:693-8.

23. Coates AS, Winer EP, Goldhirsch A, et al. Tailoring therapies--improving the management of early breast cancer: St Gallen International Expert Consensus on the Primary Therapy of Early Breast Cancer 2015. Ann Oncol 2015;26:1533-46.

24. Sun S, Liang X, Zhang X, et al. Phosphoglycerate kinase-1 
is a predictor of poor survival and a novel prognostic biomarker of chemoresistance to paclitaxel treatment in breast cancer. Br J Cancer 2015;112:1332-9.

25. Huang HP, Feng H, Qiao HB, et al. The prognostic significance of fibroblast growth factor receptor 4 in non-small-cell lung cancer. Onco Targets Ther 2015;8:1157-64.

26. Thisse B, Thisse C. Functions and regulations of fibroblast growth factor signaling during embryonic development. Dev Biol 2005;287:390-402.

27. Yu C, Wang F, Kan M, et al. Elevated cholesterol metabolism and bile acid synthesis in mice lacking membrane tyrosine kinase receptor FGFR4. J Biol Chem 2000;275:15482-9.

28. Tomlinson E, Fu L, John L, et al. Transgenic mice expressing human fibroblast growth factor-19 display increased metabolic rate and decreased adiposity. Endocrinology 2002;143:1741-7.

29. Yu S, Zheng L, Trinh DK, et al. Distinct transcriptional control and action of fibroblast growth factor receptor 4 in differentiating skeletal muscle cells. Lab Invest 2004;84:1571-80.

30. Zhao P, Caretti G, Mitchell S, et al. Fgfr4 is required for effective muscle regeneration in vivo. Delineation of a MyoD-Tead2-Fgfr4 transcriptional pathway. J Biol Chem 2006;281:429-38.

31. Li CS, Zhang SX, Liu HJ, et al. Fibroblast growth factor receptor 4 as a potential prognostic and therapeutic marker in colorectal cancer. Biomarkers 2014;19:81-5.

32. Penault-Llorca F, Bertucci F, Adelaide J, et al. Expression of FGF and FGF receptor genes in human breast cancer. Int J Cancer 1995;61:170-6.

33. Murase H, Inokuchi M, Takagi Y, et al. Prognostic

Cite this article as: Wei W, Cao S, Liu J, Wang Y, Song Q, A L, Sun S, Zhang X, Liang X, Jiang Y. Fibroblast growth factor receptor 4 as a prognostic indicator in triple-negative breast cancer. Transl Cancer Res 2020;9(11):6881-6888. doi: 10.21037/ tcr-20-1756 significance of the co-overexpression of fibroblast growth factor receptors 1, 2 and 4 in gastric cancer. Mol Clin Oncol 2014;2:509-17.

34. Quintanal-Villalonga Á, Carranza-Carranza A, Meléndez $\mathrm{R}$, et al. Prognostic role of the FGFR4-388Arg variant in lung squamous-cell carcinoma patients with lymph node involvement. Clin Lung Cancer 2017;18:667-74.e1.

35. Shim HJ, Shin MH, Kim HN, et al. The prognostic significance of FGFR4 Gly388 polymorphism in esophageal squamous cell carcinoma after concurrent chemoradiotherapy. Cancer Res Treat 2016;48:71-9.

36. Chen H, Shen DP, Zhang ZZ, et al. Fibroblast growth factor receptor 4 protein expression and clinicopathological features in gastric cancer. World J Gastroenterol 2015;21:1838-44.

37. Cancer Genome Atlas Network. Comprehensive molecular portraits of human breast tumours. Nature 2012;490:61-70.

38. Dumay A, Feugeas JP, Wittmer E, et al. Distinct tumor protein p53 mutants in breast cancer subgroups. Int J Cancer 2013;132:1227-31.

39. Bae SY, Nam SJ, Jung Y, et al. Differences in prognosis and efficacy of chemotherapy by p53 expression in triple-negative breast cancer. Breast Cancer Res Treat 2018;172:437-44.

40. Giannakakou P, Poy G, Zhan Z, et al. Paclitaxel selects for mutant or pseudo-null p53 in drug resistance associated with tubulin mutations in human cancer. Oncogene 2000;19:3078-85.

41. Thussbas C, Nahrig J, Streit S, et al. FGFR4 Arg388 allele is associated with resistance to adjuvant therapy in primary breast cancer. J Clin Oncol 2006;24:3747-55. 